\title{
Technology-Mediated Interventions and Quality of Life for Persons Living with HIVIAIDS
}

\section{A Systematic Review}

Hwayoung Cho'; Sarah Iribarren²; Rebecca Schnall ${ }^{1}$

${ }^{1}$ Columbia University School of Nursing, New York, United States;

${ }^{2}$ Department of Biobehavioral Nursing and Health Informatics, University of Washington, Seattle, United States

\section{Keywords}

Technology-mediated interventions, internet and the web technology, eHealth, telemedicine and telehealth, mobile computing and communication, mHealth, HIVIAIDS, quality of life

\section{Summary}

Background: As HIV/AIDS is considered a chronic disease; quality of life (QoL) has become an important focus for researchers and healthcare providers. Technology-mediated interventions have demonstrated improved clinical effectiveness in outcomes, such as viral suppression, for persons living with HIVIAIDS (PLWH). However, the evidence to support the impact of these interventions on QoL is lacking.

Objectives: The aim of this paper was to assess the impact of technology-mediated interventions on QoL and to identify the instruments used to measure the QoL of PLWH.

Methods: For this review we followed the PRISMA guidelines. A literature search was conducted in PubMed, CINAHL, Cochrane, and EMBASE databases in April 2016. Inclusion criteria limited articles to those with technology-mediated interventions as compared to usual care; articles with the population defined as HIV-infected patients; and articles with QoL measured as a health outcome in randomized controlled trials. The Cochrane Collaboration Risk of Bias Tool was used to assess study quality.

Results: Of the 1,554 peer-reviewed articles returned in the searches, 10 met the inclusion criteria. This systematic review identified four types of technology-mediated interventions and two types of QoL instruments used to examine the impact of technology-mediated interventions on PLWH. Four studies of technology-mediated interventions resulted in improvement in QoL. Four studies considered QoL as a secondary outcome and resulted in a negative or neutral impact on QoL. Overall, four studies had a low risk of bias, one study had a moderate risk of bias, and the other five studies had a high risk of bias.

Conclusions: The evidence to support the improvement of QoL using technology-mediated interventions is insufficient. This lack of research highlights the need for increased study of QoL as an outcome measure and the need for consistent measures to better understand the role of technology-mediated interventions in improving QoL for PLWH. 


\section{Correspondence to:}

Hwayoung Cho, MPhil, MSN, RN

Columbia University School of Nursing

617 West 168th Street, New York, NY 10032, United

States

Email: hc2787@columbia.edu
Appl Clin Inform 2017; 8: 348-368

https://doi.org/10.4338/ACI-2016-10-R-0175

received: October 16, 2016

accepted: January 27, 2017

published: April 12, 2017

Citation: Hwayoung Cho, Sarah Iribarren, Rebecca Schnall. Technology-Mediated Interventions and Quality of Life for Persons Living with HIVIAIDS: A Systematic Review. Appl Clin Inform 2017; 8: 348-368 https://doi.org/10.4338/ACl-2016-10-R-0175

\section{Funding}

This work was supported by the Agency for Healthcare Research and Quality under award number R21HS023963 (PI: Schnall) and the National Institute of Nursing Research of the National Institute of Health under award number R01NR015737 (PI: Schnall). At the time of this study, Dr. Sarah Iribarren was funded by a Comparative and Cost-Effectiveness Research Training for Nurse Scientists Award (T32-NR014205; PI: Stone) by the National Institute of Nursing Research of the National Institutes of Health. The content is solely the responsibility of the authors and does not necessarily represent the official views of the Agency for Healthcare Research and Quality or the National Institute of Health. 


\section{Background}

There were an estimated 36.7 million persons living with HIV/AIDS (PLWH) in the world at the end of 2015 [1]. Due to advances in treatment in the past three decades, the survival of PLWH has increased and HIV/AIDS is considered a chronic disease [2]. As a result, quality of life (QoL) for PLWH has become an important focus for researchers and healthcare providers [3]. The World Health Organization (WHO) has defined QoL as "individuals' perceptions of their position in life in the context of the culture and value systems in which they live and in relation to their goals, standards, expectations and concerns" [4]. As PLWH are burdened with opportunistic infections and lifetime treatments with potential adverse effects, there has been growing interest in understanding PLWH's QoL as a significant health outcome measure, and its enhancement is an important goal in HIV/AIDS care [5-8].

Technology-mediated interventions, utilizing technologies as an intervention, have the potential not only to support lifelong engagement and improvement in the HIV care continuum but also to improve the QoL of PLWH [9-12]. Technology-mediated interventions have demonstrated efficacy to improve clinical effectiveness in outcomes of medication adherence and viral suppression for PLWH [13-15]. Such interventions could also potentially improve QoL by improving communication between patients and providers and communication among diverse providers for a multidisciplinary care approach, increasing treatment monitoring, supporting information/resource delivery and enhancing quality of care to PLWH [16-20]. Several factors have been identified as related to the QoL of PLWH, including medication adherence [21], symptom management [22], HIV-related stigma [23], social support [24], and access to health care resources and social services [25]. Technology-mediated interventions can support HIV-related treatment and management, providing social support and improving service delivery [26].

However, the evidence to support the impact of technology-mediated interventions on QoL is lacking. Despite the potential of these interventions and the increased recognition of the importance of QoL, the extant previous literature has focused on the effect of technology-mediated interventions on other clinical outcomes. To our knowledge, this is the first systematic review to focus on QoL as an outcome measure. Therefore, our manuscript adds to the literature by evaluating the evidence of technology-mediated interventions on QoL and exploring how it is being measured.

\section{Objectives}

As a preliminary step in addressing this gap, the objective of this review was to evaluate the impact of technology-mediated interventions on the QoL of PLWH as a health outcome, and to assess the instruments used to measure QoL. This evaluation contributes to the decision-making on the utility in investing in technology-mediated interventions for improving QoL.

\section{Methods}

This literature review systematically identified randomized controlled trials (RCTs) that evaluated the effect of technology-mediated interventions on QoL for PLWH. In this review, technology-mediated interventions were categorized as eHealth, telehealth, and mHealth, which are not mutually exclusive as interventions. Since eHealth is the use of a wider range of information and communication technologies (ICT) for health [27], and telehealth and mHealth are areas of eHealth [28, 29], we defined those types of technology-mediated interventions as follows: 1) eHealth; use of internet for health including electronic medical records (EMR) [9], 2) telehealth; use of telecommunication technologies to support long-distance clinical health care, and patient and professional health-related education as a broader scope of telemedicine [28], and 3) mHealth; use of mobile technologies such as mobile phones and Personal Digital Assistants (PDAs) for health [29]. A phone-call-based interventions using landline telephones or mobile phones were categorized into telehealth. This review followed the Preferred Reporting Items for Systematic Review and Meta-Analysis (PRISMA) Guidelines [30]. 


\subsection{Search strategy}

A comprehensive search strategy was developed in collaboration with a research librarian at Columbia University Medical Center. Searches were conducted in April 2016 without date limits of publication in the following four databases: PubMed, EBSCO CINAHL, Cochrane Library, and EMBASE. Further searches were run using the following sources: institutional websites including the WHO, the National Institute for Health and Care Excellence (NICE), and the Joint United Nations Program on HIV/AIDS (UNAIDS). To capture all relevant studies, a 'hand' search of references identified reviews was also conducted. Search terms used in the title, abstract, or author keywords were as follows: (text OR text message OR text messaging OR short message service OR SMS OR mobile application ${ }^{\star}$ OR cell phone $e^{\star}$ OR cellular phone $e^{\star}$ OR smartphone $e^{\star}$ OR mobile phone ${ }^{\star}$ OR mobile health OR mhealth OR computers, handheld OR personal digital assistant OR PDA OR eHealth OR e-Health OR electronic health OR online OR social networking OR information system* OR reminder system* OR telemedicine OR telehealth) AND (HIV OR HIV infection* OR Human Immunodeficiency Virus OR AIDS OR AIDS virus OR Acquired Immunodeficiency Syndrome). MeSH headings and the exact text word were used.

\subsection{Study Selection and Data Extraction}

We used Covidence [31], a web-based program designed to support the systematic review process, to facilitate screening at the title/abstract, and full text level, as well as data extraction, adjudication of disagreements, and confirmation of data. During each screening stage, two reviewers independently assessed eligibility and differences were resolved by consensus. The following information was extracted from the studies: the name of the first author, publication year, locations of the studies, type of studies, target population, sample size, interventions, duration of studies, outcomes, and key conclusions. Data extraction was conducted by two independent reviewers, and a third consulted in instances of uncertainty.

\subsection{Eligibility Criteria}

Inclusion criteria were as follows: 1) original research manuscript; 2) studies that were RCTs that assessed the impact of technology-mediated interventions as compared to usual care or any other intervention; 3) defined the population of interest as PLWH; 4) examined QoL as a health outcome; 5) available in the English language and full text. We excluded poster sessions, presentations, protocols, letters, comments, editorials, correspondences or grey literature (e.g., blogs, newsletters, videos).

\subsection{Quality Assessment}

The quality appraisal was conducted using the Cochrane Collaboration Risk of Bias Tool (CCRBT) [32] to ascertain overall study quality. The CCRBT is a validated tool that was designed to evaluate the risk of bias in RCTs [32]. It evaluates six different domains: 1) adequacy of sequence generation, 2) concealment of allocation, 3) blinding, 4) completeness of follow-up, 5) freedom from reporting bias, and 6) other forms of bias. Each domain is evaluated as 'yes' (low risk of bias), 'no' (high risk of bias) or 'unclear' (uncertain risk of bias). Each study is then assigned an overall grade of high, moderate, or low risk of bias. Per the risk of bias guidelines, overall assessment of quality is assigned to each individual study according to the following criteria: low risk of bias if the first three domains are scored as 'yes' and no important concerns related to the last three domains are identified; moderate risk of bias if one or two domains are scored as not clear or not done; and high risk of bias if more than two domains are scored as not clear or not done. 


\section{Results}

\subsection{Study Selection}

The initial searches resulted in 1,554 articles. We identified an additional 66 articles through hand searches. After deduplication 1,108 original articles remained. During screening, 944 studies were excluded based on title and abstract. During a full-text review, an additional 154 articles were excluded based on inclusion/exclusion criteria. A total of 10 studies that met the criteria were included in the systematic review. Figure 1 displays the results of the search and study selection.

\subsection{Study Characteristics}

An overview of study characteristics for the 10 eligible studies is presented in $>$ Table 1 . These are: Gustafson, 1994 [33]; Huang, 2013 [34]; Leon, 2011 [35]; Mbuagbaw, 2012 [36]; Millard, 2015 [37]; Proeschold-Bell, 2010 [38]; Pyne, 2011 [39]; Robbins, 2013 [40]; Wang, 2010 [41]; and Wu, 2006 [42]. All studies derived their estimate of the effectiveness of technology-mediated interventions on QoL from RCTs that assessed the differences between technology-mediated intervention groups and control groups. Of the RCTs, six [33, 34, 38-41] were multi-site RCTs, and the other four [35-37, 42] were single-site RCTs including a pilot study [37]. One study was reported as a secondary analysis using data from RCTs [42]. Five studies were based in the United States [33, 38-40, 42], two studies in China [34, 41], and one each in Spain [35], Cameroon [36], and Australia [37]. One study was published in 1994 [33], and the other nine studies were published between 2006 and 2015. Sample sizes varied, ranging from 62 [42] to 333 [40] participants. All participants in eligible studies were adult PLWH including those who were antiretroviral therapy (ART) treatment-naive and/or ART treatment-experienced patients, PLWH with depression [39], gay men [37], and heroin-experienced users [41]. The duration of studies ranged from 7 weeks [37] to 160 weeks [40].

\subsection{Study Findings}

\subsubsection{Type of Technology-Mediated Interventions}

For the purpose of analysis, technology-mediated interventions used in the 10 reviewed studies were classified into four main categories: eHealth $(n=3)$, telehealth $(n=4)$, eHealth+telehealth $(n=1)$, and mHealth $(n=2)$. Table 2 displays a summary of technology-mediated interventions used in eligible studies. The following section briefly describes the technology-mediated interventions classified in the four main categories.

eHealth ( $n=3)$ : computer-based system, Internet-based program, and Health Information Exchange (HIE)

In a study using a computer-based system, CHESS (Comprehensive Health Enhancement Support System) offered information, social and emotional support, and problem-solving tools in health crises [33]. For an Internet-based program, an online self-management program called Positive Outlook was assessed for its feasibility, acceptability, and effectiveness for gay men living with HIV [37]. Patient information between care providers among six infectious disease clinics paired with 9 case management agencies was exchanged using electronic health records and printouts inserted into charts [38].

\section{Telehealth $(n=4)$ : phone calls and telemedicine}

Phone calls were the most commonly used tool and the primary platform to evaluate the impact on QoL in PLWH. In one study [34], phone calls were made every two weeks to patients in the intervention group. During the phone call intervention, two trained nurses used a semi-structured dialogue to elicit the reasons and difficulties in symptom management and treatment adherence. In another study [40], a site-nurse initiated adherence and symptom support phone calls every 1 to 3 days after starting ART and then every 8 weeks. The other phone call intervention was also carried out every two weeks [41]; however, this was used to compliment a home visit intervention. The phone calls intervention by trained nurses was designed to be semi-structured to assess the adherence level, 
inquire how the patients had been implementing their medication plan, identify common barriers, and ask information about general emotional, eating, and sleeping problems. Virtual Hospital was a telemedicine intervention that offered integrated online patient monitoring by a multidisciplinary care team ( 9 infectious diseases specialists, 3 nurses, 1 psychologist, 1 psychiatrist, 3 pharmacists, and 1 social worker), allowing the professionals to remotely follow up with patients who have access to their own clinical and pharmaceutical files [35]. Virtual Hospital offered four main services: virtual consultations, telepharmacy, virtual library and virtual community.

\section{eHealth plus telehealth $(n=1)$ : Web-based decision support system + telephone-based moni- toring}

In a study using eHealth with telehealth [39], the HIV Translating Initiatives for Depression into Effective Solutions (HITIDES) intervention consisted of an offsite HIV depression care team (a registered nurse depression care manager, pharmacist, and psychiatrist) that delivered up to 12 months of collaborative care backed by a Web-based decision support system with telephone-based monitoring.

\section{mHealth $(\mathrm{n}=2)$ : text messaging and programmable mobile device}

The Cameroon mobile phone SMS (CAMPS) intervention [36] used text messaging via short message service (SMS) to deliver a behavior change intervention and retain participants' attention. Each participant in the intervention group received motivational and reminder messages. A new message from a series of 11 messages was sent weekly. Another study used a programmable mobile device intervention called Disease Management Assistance System (DMAS) [42]. The DMAS, an electronic device programmed with an individualized ART regimen, with verbal reminder messages regarding dosing times, was evaluated for its feasibility for use in HIV-infected patients. The DMAS device also recorded dosing date and time when the patient pushes a response button, and these data could be uploaded to a PC, used to generate reports.

\subsubsection{QoL instruments}

QoL instruments were classified into two main types: generic and HIV-specific. $>$ Table 3 displays a summary of QoL instruments used in the studies included in this review.

\section{Generic $(n=6)$}

Generic types of QoL instruments were the most commonly used ( $n=6,60 \%)$. Of the generic types, the Short Form (SF)-12 and SF-36 were used to measure QoL in two studies [36, 38]. The SF-12 and SF-36 provide two summary measures: the physical component summary and the mental component summary, which were utilized as the primary outcome measures of self-reported health. The SF-12 is weighted and summed to provide easily interpretable scales for physical and mental health. The SF-36 is a 36-item instrument validated in the Medical Outcomes Study to assess important QoL domains relevant to patients suffering from a wide range of medical conditions [43]. The SF-36 consists of eight QoL domains: physical functioning, role functioning (physical and emotional), bodily pain, general health, vitality, social functioning, and mental health. Subscales are scored from 0 to 100 , with 100 indicating better health [38]. The SF-12 is a shortened form of the SF-36 Health Survey and it can be explained about $90 \%$ of the variation in the same summary measures of the SF-36 [44, 45]. One study used the Mini-International Neuropsychiatric Interview (MINI) to evaluate QoL.[35] The MINI is a widely used psychiatric structured diagnostic interview instrument, containing 130 questions with only 'yes' or 'no' answers [46, 47]. In the study, the MINI assessed various aspects including mental and physical health, cognitive and social functioning, energy levels and vitality, perceived social support, sleep, and sexuality. MINI has been validated in HIV patients [48]. In another study, the Quality of Well-Being Self-administered Scale (QWB-SA) was used and the QWB-SA score was derived from general population preference weights, and it ranges from death (0.0) to perfect health (1.0) [39]. The Chinese version of the WHO Quality of life (WHOQOLBREF) was also used.[41] WHOQOL-BREF is a 26-item multiple-choice questionnaire, including one item for general QoL, one item for health-related QoL and twenty-four items belonging to four domains: seven items in physical, six items in psychological, three items social, and eight items environmental. Individual items are rated on a five-item Likert scale. Since the number of items differs in 
the four domains, the score of each domain is calculated by multiplying the average of the scores of all items; hence, the domain scores range from 4 to 20. The Chinese version of the WHOQOL-BREF was validated in the Chinese population [49]. Gustafson et al. [33] reported the average QoL score for eight dimensions including social support, cognitive functioning, active life, active participating in health care, negative emotions, depression, physical functioning, and level of energy.

\section{HIV specific $(n=4)$}

The following four HIV-specific QoL instruments were used [34, 37, 40, 42]. The World Health Organization Quality of Life Instrument-HIV Abbreviated version (WHOQOL-HIV BREF) is a HIVspecific instrument, comprised of two general items for the assessment of general health and overall QoL along with 29 additional items that cover six domains: physical well-being; psychological status; level of independence; social relationships; environment; and spirituality/religion/personal beliefs $[34,50]$. There are four items in the physical, five items in the psychological, four items in the level of independence, four items in the social relationships, eight items in the environment, and four items in the spiritual domain. The score is calculated the same way as the Chinese version of the WHOQOL-BREF. The Patient Reported Outcomes Quality of Life-HIV (PROQOL-HIV), used in another study [37] includes 8 domains of physical health and symptoms, body change, social relationships, intimate relationships, stigma, emotional distress, health concerns, and treatment impact [51]. The AIDS Clinical Trials Group (ACTG) Multidimensional Health Status and the Quality of Life (QL0601-0602) instrument was also used [40]. The QL0601 is an overall health status assessment, and the QL0602 is a multidimensional health status assessment, including 9 domains with 21 items: overall health, general health perceptions, physical functioning, role functioning, pain, social functioning, mental health, energy, and cognitive functioning. Wu et al. [42] administered a battery of QoL instruments including the Medical Outcomes Study HIV Health Survey (MOS-HIV) with the Centers for Epidemiologic Studies Depression Scale (CES-D), Instrumental Activities of Daily Living (IADLs), and additional role-functioning items. The MOS-HIV is a brief, comprehensive HIVtargeted measure of QoL, including 10 dimensions: pain, physical function, role function, social function, mental health, energy/fatigue, health distress, cognitive function, health perception, and overall QoL [52]. The scores for each domain were calculated and transformed linearly into a 0 to 100 scale. Twenty items on the CES-D covered guilt and loneliness, appetite, sleep, psychomotor problems, mood, and depressive symptoms using a four-point scale that ranges from 0 to 3 [53]. The 15 items of the IADLs assessed patients' abilities to perform everyday tasks such as dressing, bathing, money management, home care, and eating, ranging from 0 to 2 [54].

\subsubsection{Impact of Technology Mediated Interventions on QoL}

The findings of the impact of technology-mediated interventions on QoL were inconsistent in this review and they have been classified into three categories: positive, negative, and neutral. Four studies with a positive impact $[33,34,37,41]$, one study with a negative impact [42], and five studies with a neutral impact $[35,36,38-40]$ for technology-mediated interventions on QoL were identified.

\section{Positive ( $n=4) ; 2$ eHealth and 2 telehealth}

Four studies showed a positive impact of technology-mediated interventions on QoL. The types of technology-mediated interventions were eHealth (computer-based system [33] and Internet-based program [37]) and telehealth (phone calls) [34, 41]. A study using a computer-based system showed significantly higher QoL in several dimensions including social support and cognitive functioning [33]. Also, significant improvements by Internet-based program intervention group participants between baseline and follow-up were found for physical health and symptoms,; body change, social relationships, intimate relationships, stigma, emotional distress, and health concerns [37]. In the phone calls intervention group, there was a significant increase in QoL in the domains of physical, psychological, social and environmental (15.3\%; 18.4\%; 18.5\%; 25.6\%), while there was a slight increase in social and environmental domains in the control group (1.6\%; 1.8\%) [41]. Also, in the group of treatment-naive patients, significant improvements in QoL among patients with the phone calls intervention compared to those without the intervention were observed in four QoL domains - 
physical well-being, level of independence, environment and spiritual/religion/personal beliefs-, but there were no differences among the treatment-experienced patients [34].

\section{Negative $(n=1) ;$ mHealth}

One study that used a programmable mobile device intervention showed the opposite results of the impact of technology-mediated interventions on QoL [42]. The QoL score decreased in the intervention group, while the QoL score was increased in the control group.

\section{Neutral ( $\mathrm{n}=5$ ); 2 telehealth, 1 eHealth, 1 eHealth+telehealth and 1 mHealth}

Two studies of telehealth using telemedicine [35] and phone calls [40] showed no difference in QoL scores between technology-mediated intervention and the control groups. Also, in three more studies using, eHealth (HIE) [38], eHealth plus telehealth (web-based decision support system with telephone-based monitoring) [39], and mHealth (text messaging) [36], there were no differences in QoL in the technology-mediated intervention group.

\subsubsection{Type of endpoints of QoL}

A clinical trial endpoint (or outcome) is defined as a measure that allows researchers to decide whether the null hypothesis of a clinical trial should be accepted or rejected. The endpoints are classified as primary and secondary [55]. In four studies [36, 39, 40, 42], QoL was a secondary endpoint for evaluating the impact of technology-mediated interventions and the impact of technology-mediated interventions was identified as negative or neutral. In the other six studies considering QoL as a primary outcome, QoL was measured, along with multiple outcomes or ART adherence.

\subsubsection{Study Quality}

The results of the assessment of study quality using CCRBT are reported in $>$ Figure 2, and the Cochrane risk of bias summary is reported in Figure 3 . Overall, four studies $[34,36,37,39]$ had a low risk of bias, one study study [40] had a moderate risk of bias, and the other five studies [33, 35, $38,41,42]$ had a high risk of bias.

\section{Discussion}

This systematic review identified four types of technology-mediated interventions and two types of QoL instruments used to examine the impact of technology-mediated interventions on QoL in HIV/AIDS care. Four studies of technology-mediated interventions resulted in improvement in QoL. Four of the 10 eligible studies considered QoL as a secondary outcome and reported the negative or neutral impacts of technology-mediated interventions on QoL.

We included a total of 10 studies that met the criteria. There were three studies identified that included QoL measures as an assessment tool [24, 25], included QoL only at baseline [56], or included but not reported QoL results [57] and therefore were not included in this review. Swendeman et al. used a QoL scale as an assessment tool within the application of a technology-mediated intervention for supporting self-monitoring; however, QoL was not measured as an outcome [24, 25]. We also excluded a study using cell phone-delivered interventions for smokers living with HIV/AIDS since they assessed QoL only at baseline [56]. Lastly, a multi-site RCT of HIV-infected adults was conducted in Kenya to evaluate the effect of a mobile phone SMS. The primary outcomes included selfreported adherence to ART and suppression of HIV viral load at 12 months scheduled follow-up, and secondary outcomes included improvements in health, QoL, social and economic factors, and retention on ART [57]. Although QoL was presented as being measured, the result of QoL was not reported and therefore the study was excluded from this review. There was also a study using mHealth, particularly Medication Event Monitoring System Cap (MEMS Cap) [58]; however, it was used in both groups of a voucher-based intervention and control then the study was excluded from this review. Although there were few studies included in this review, we did identify two published study protocols that include QoL as an outcome. A study protocol for WelTel Retain aims to evaluate the effect of weekly SMS communication (WelTel) on retaining pre-ART patients in care, and this study determines the cost-effectiveness of the intervention [59]. The primary outcome will be 
12-month retention in care and key secondary outcomes will be retention in stage 1 HIV care and incremental cost-effectiveness ratio. QoL will be measured as an additional secondary outcome. Another protocol outlines a study to investigate whether a text messaging intervention, called Connect4Care (C4C), that supports healthy behaviors, encourages consistent engagement with care, and promotes antiretroviral persistence, can improve viral suppression (primary outcome) and retention in care (key secondary outcome) among patients in San Francisco [60]. Similarly, QoL will be measured as one of multiple secondary outcomes. While these protocols were excluded in this review, they are described here since they will have future QoL outcomes for technology-mediated interventions in RCTs.

Six studies had either a moderate or high risk of bias in the overall assessment of quality. As CCRBT is a tool designed to evaluate the risk of bias in RCTs, the overall quality assessment grades are heavily weighted on the judgements assigned to the first three domains of random sequence generation, allocation concealment and blinding. The domain of blinding, in particular, showed an unclear or high risk of bias in the included studies. Blinding refers to the process by which study participants, health providers and investigators are kept unaware of intervention allocations after inclusion of participants into the study [56]. Lack of blinding of participants or health providers could bias the results by affecting the actual outcomes of the participants in the trial. The lack of blinding in RCTs has been shown to be associated with more exaggerated estimated intervention effects, by $9 \%$ on average, measured as odds ratio [61]. Due to the nature of the interventions, it is not always possible for patients to be blinded with regard to group allocation. However, some studies used blinding of the outcome assessors to patient allocation. For example, trained interviewers and data analyst were blinded to group allocation of patients, who were only identified by their phone numbers and their sequential trial numbers.

Out of the 10 reviewed studies, four revealed that technology-mediated interventions improved QoL for PLWH $[33,34,37,41]$. The types of technology-mediated interventions showing the positive impacts on QoL were eHealth and telehealth interventions. The two telehealth interventions were the same as phone calls interventions. In one study, the improvement of QoL was supported via phone calls intervention combined with home visits among heroin-experienced users [41]. Previous studies of QoL in HIV-infected populations showed that current drug use was associated with lower mental health and Qo $[5,16,17]$. Although the study sample included some active drug users [41], the positive effect of phone calls intervention on QoL were demonstrated. However, the effect of the phone calls intervention should be identified separately since nurses' home visits could affect the QoL of PLWH as well. Another intervention with phone calls supported a better QoL among treatment-naive patients, but no changes among treatment-experienced patients [34]. This was not consistent with the other study assessing the impact of the phone-call-based intervention for 160 weeks [40]. Among HIV patients starting ART, there were no significant changes in QoL reported and therefore it is hard to conclude that the phone-call-based intervention can lead to better QoL for PLWH. Out of three eHealth interventions included in our review, two studies showed the positive impacts of technology-mediated interventions on QoL. The specific types of eHealth interventions were a computer-based system and an Internet-based program. The computer-based system, CHESS, included 6 different topics of HIV/AIDS, breast cancer, acquaintance rape, academic failure, alcoholics, and stress management. However, only the HIV/AIDS module was evaluated in the study [33]. CHESS transmitted data via modem to a central host computer. Considering the study publication year of 1994, the trend of eHealth interventions might have changed from a computer-based system via modem to an online program via Internet [37].

In contrast to the positive effect of technology-mediated interventions on QoL, a programmable mobile device providing a verbal medication reminder, namely DMAS, resulted in deterioration of the patient's QoL [42]. As the authors posited, this might be due to a violation of the patient's privacy by the reminder $[34,42]$. In five of the 10 reviewed studies, the impact of technology-mediated interventions was identified as neutral, of which two types of technology-mediated interventions were categorized into telehealth (telemedicine [35] and phone calls [40]), eHealth (HIE) [38], eHealth plus telehealth (web-based decision support system with telephone-based monitoring) [39], and mHealth (text messaging) [36]. mHealth studies have demonstrated the potential of delivering health behavior change interventions, and the mHealth interventions have been expected to further improve QoL [62]; however, the impact of two mHealth interventions on PLWH's QoL in this re- 
view was shown as negative or neutral. It is essential to further investigate the effectiveness on QoL in mHealth research.

In summary, the findings from this review do not provide conclusive evidence on which technology-mediated intervention is most effective since the findings across studies are inconsistent. As the evidence grows we may be able to determine what type of technology-mediated interventions most impacts QoL in PLWH. Although telehealth, particularly phone calls interventions, seem to be relatively acceptable and effective in improving QoL for PLWH, fewer studies have examined the overall impact of technology-mediated interventions on QoL in HIV/AIDS care. The effectiveness of technology-mediated interventions using telephones on QoL in other chronic diseases has been demonstrated. For instance, one trial reported improved QoL for patients with chronic heart failure receiving a mobile phone-based telemonitoring intervention [63]. Also, QoL was significantly improved among patients with chronic disease who underwent a telephone-based programme to adjust medication [21]. As HIV/AIDS is a chronic disease, it might be more feasible to demonstrate the impact of technology-mediated interventions on QoL for PLWH in future research.

In addition, a variety of QoL instruments are currently being used for PLWH. Based on the analysis, we classified the QoL instruments as generic and HIV-specific. They were validated instruments and recommended over structured interviews except one not clearly described [33]. Each study used a different QoL instrument and the instrument was described in detail including domains/subscales in the section of Results. To measure QoL related to technology-mediated interventions in HIV/ AIDS care, generic QoL instruments were more commonly used, compared to HIV-specific instruments. A generic instrument allows for comparability between PLWH, other diseases and cancers, and the general population, as normative data exist for many countries [22]. As generic instruments may not be very sensitive in detecting effects that are associated with specific diseases, the combination of a generic and specific health-related QoL instrument is most informative [23]. Future study of technology-mediated interventions should include patient-reported outcomes such as QoL with a validated instrument for PLWH so that patients can be informed of the impact in these domains.

Finally, in four studies describing QoL as a part of secondary outcomes, the impact of technology-mediated interventions was identified as negative or neutral. In a study assessing QoL as a part of secondary outcomes [36], details were not described clearly. The resulting mean QoL score was presented in a table. Primary endpoints measure outcomes that will answer the primary (most important) question, and sample size power calculations are performed based on the primary outcome of the study in RCTs [64]. Given that HIV is a chronic disease with accompanying potential adverse effects, QoL is valuable enough as a primary outcome in PLWH. There was no study that clearly defined QoL or the aspects of QoL. It might also be relevant to evaluate QoL as one of secondary outcomes. It is important to specify QoL and its aspect through the use of International Classification of Functioning Disability and Health (ICF) [65] as a conceptual framework while planning a study on the impact of technology-mediated interventions on QoL for PLWH. This would help to more consistently define/measure QoL across studies.

\section{Limitations}

There were several limitations that should be considered when interpreting the findings of this reviews. First, the number of eligible studies was quite small. There were a few study protocols in the literature that were not included in our review, which indicates that the studies might be ongoing. An additional limitation is the possibility that relevant studies may have been missed, particularly in the grey literature. There may be unpublished material, which could change the findings, if we had access to this data. Considering the limited number of studies, the varied outcome measurement across studies, and methodological quality of the suggested studies, the results were not amenable to statistical solutions. Lastly, while we appreciate QoL comprises various constructs such as daily activities, psychological well-being, or social interaction, our study was limited to studies with a QoL measure as to allow for consistency and ability to compare of outcomes. 


\section{Conclusions}

Technology-mediated interventions have been considered an effective tool in improved clinical outcomes in HIV/AIDS care. QoL has been recognized as an important outcome for PLWH, yet the evidence to support the improvement of QoL using technology-mediated interventions is insufficient. This lack of research highlights the need for increased use of QoL as an outcome measure and more consistency in measurements to better understand the role of technology-mediated interventions in improving QoL. Future studies of technology-mediated interventions should include QoL with a validated instrument for PLWH. Future studies should also include the combination of a generic and HIV-specific QoL instrument, as this is considered most informative.

\section{Multiple Choice Question}

Which of the following is not included in technology-mediated interventions?

A) Telemedicine

B) Decision support system

C) Voucher reinforcement

D) Programmable mobile device

- Answer: C. Voucher reinforcement

Technology-mediated interventions refers to utilize a various types of technologies as an intervention including eHealth, telehealth, and $\mathrm{mHealth}$. A Voucher reinforcement intervention does not describe the use of technology.

\section{Clinical Relevance Statement}

Although technology-mediated interventions have been considered an effective tool in HIV/AIDS care, and quality of life has been recognized as an important outcome for persons living with HIV, the impact of technology-mediated interventions on quality of life still remains unclear. This review has implications for future research evaluating the effectiveness of technology-mediated interventions on quality of life as a primary outcome using a validated instrument in persons living with HIV.

\section{Conflicts of Interest}

The authors declare that they have no conflicts of interest in the research.

\section{Human Subjects Protections}

Human and/or animal subjects were not included in this review.

\section{Acknowledgments}

The authors thank Dr. Suzanne Bakken for her thoughtful review of this manuscript. 


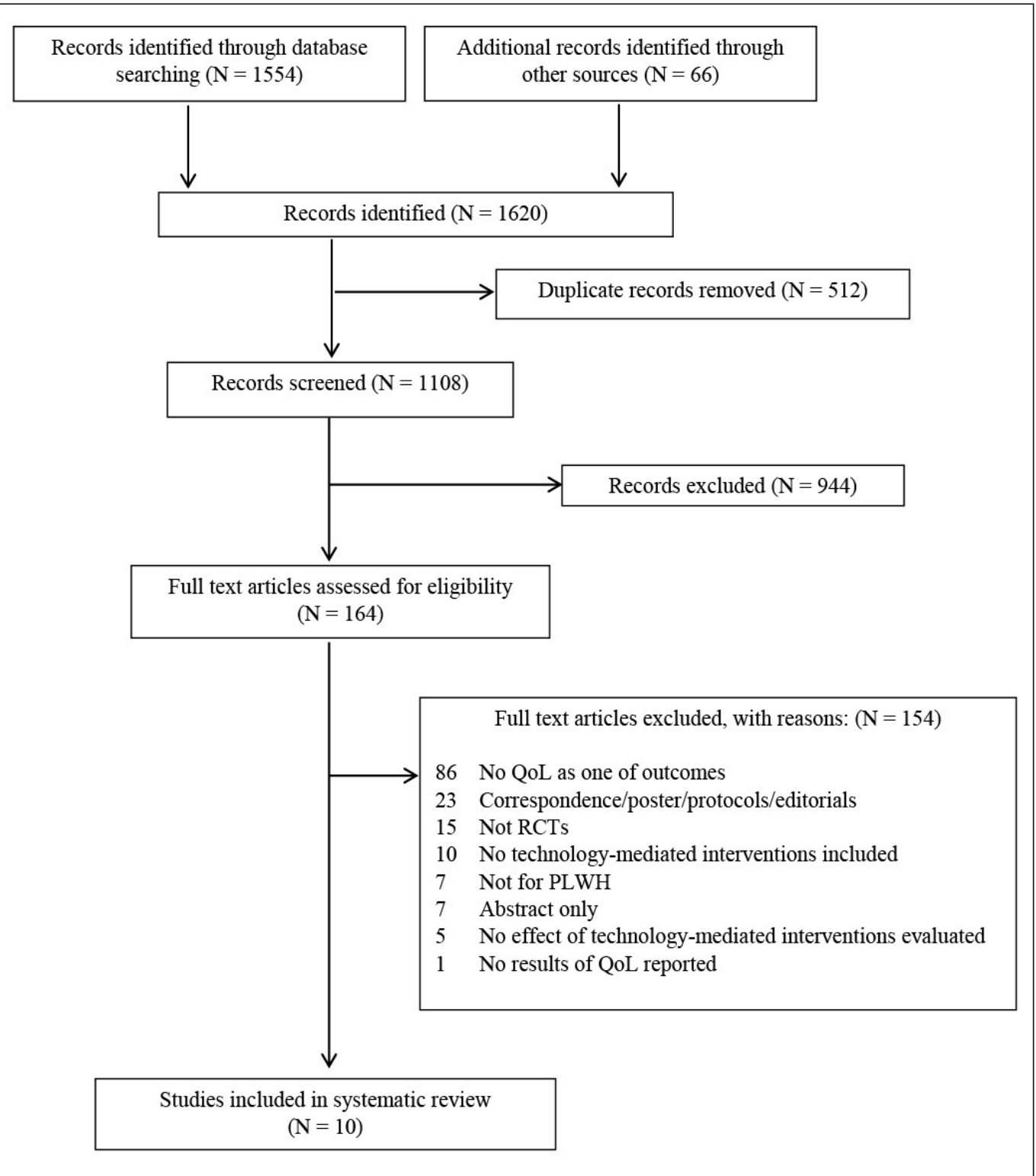

Fig. 1 Summary of the literature search 


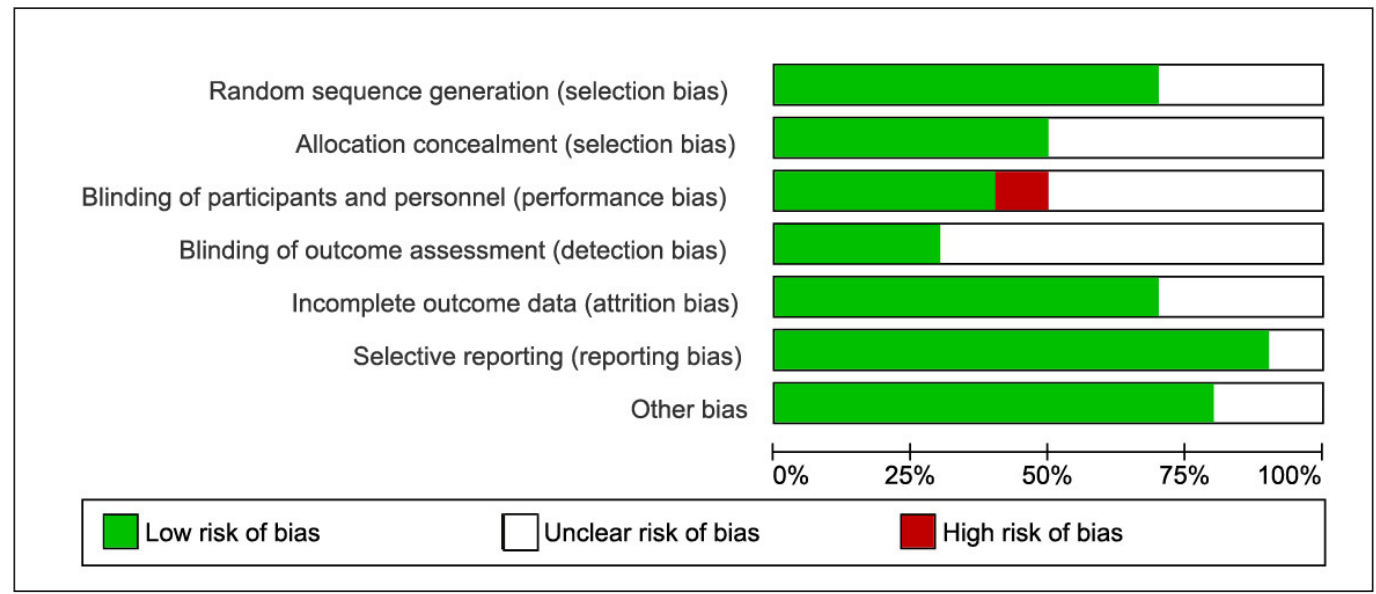

Fig. 2 Quality Assessment: Cochrane Collaboration Risk of Bias Tool (CCRBT)(18)

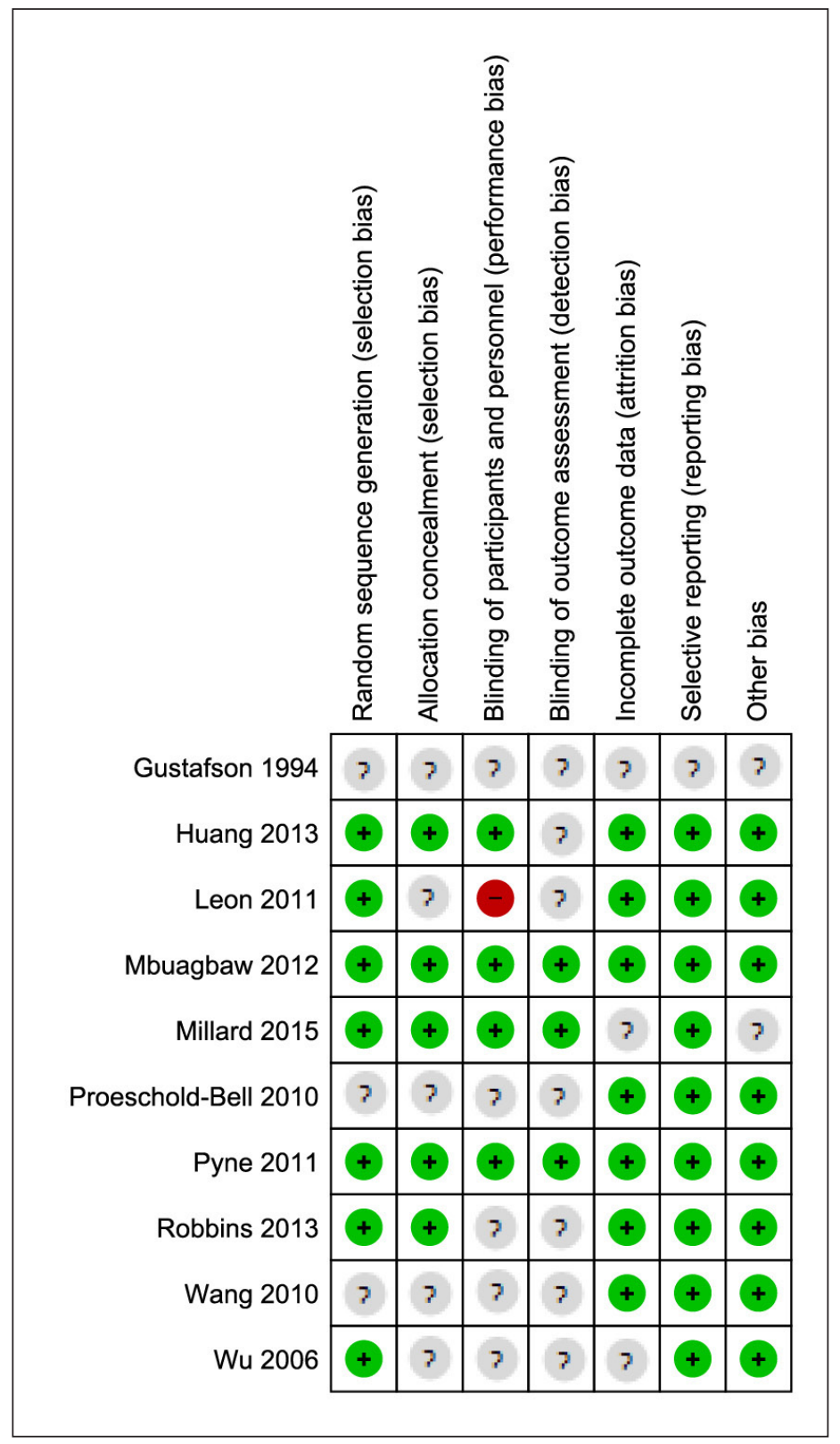

Fig. 3

Summary of Cochrane Collaboration Risk of Bias Tool (CCRBT)(18) 


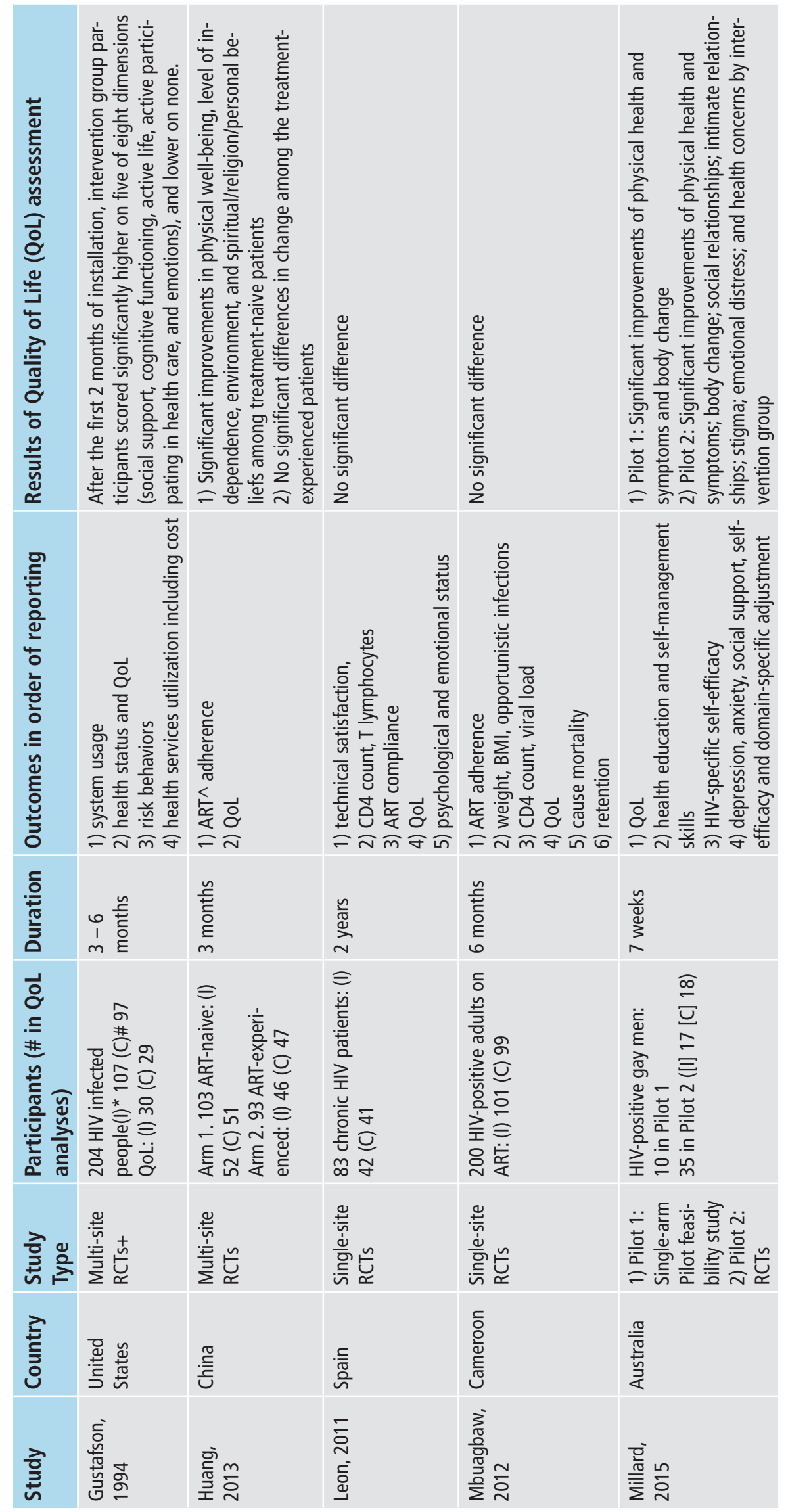




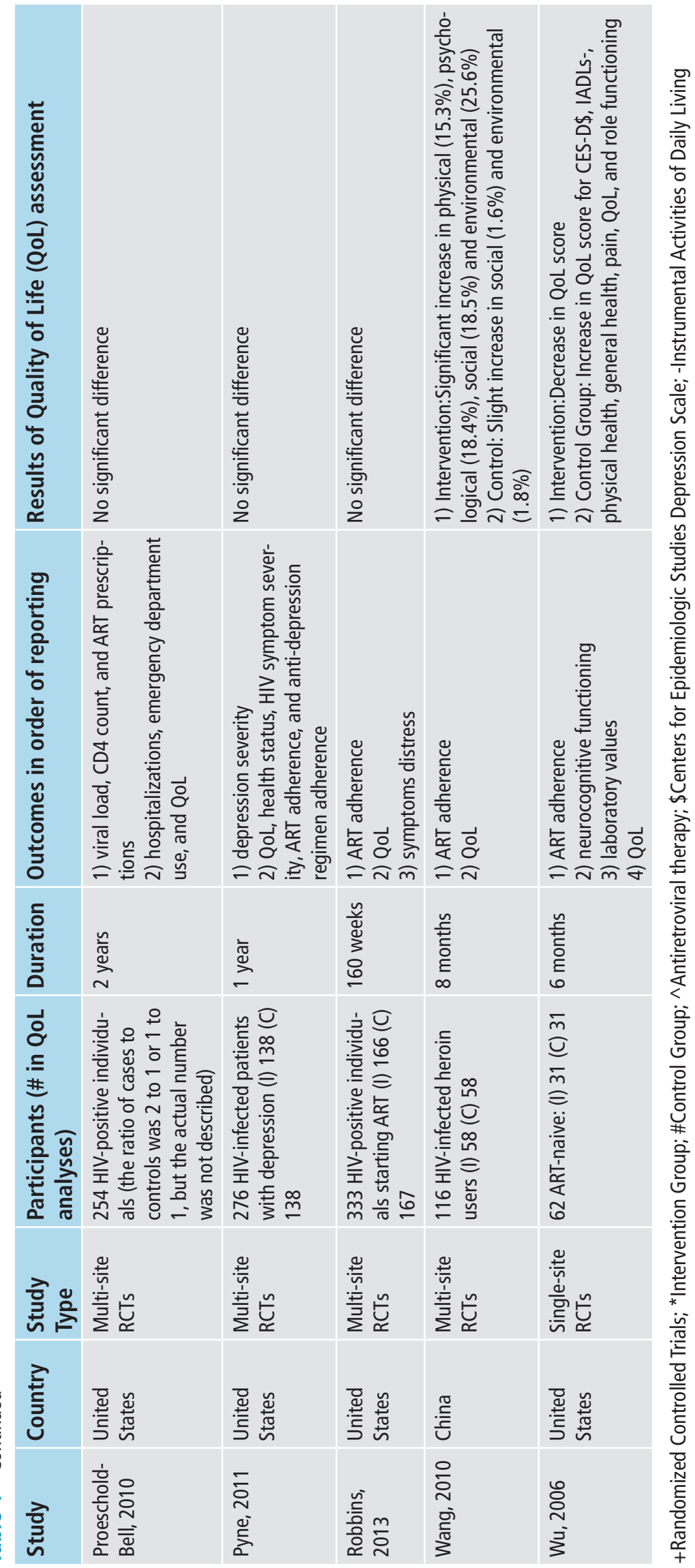


Table 2 Summary of Technology-Mediated Interventions used in eligible studies

\begin{tabular}{|c|c|c|c|}
\hline Study & $\begin{array}{l}\text { Type of } \\
\text { Technology- } \\
\text { Mediated In- } \\
\text { terventions }\end{array}$ & $\begin{array}{l}\text { Technology- } \\
\text { Mediated } \\
\text { Interventio } \\
\text { ns used }\end{array}$ & Description \\
\hline $\begin{array}{l}\text { Gustaf- } \\
\text { son, } 1994\end{array}$ & eHealth & $\begin{array}{l}\text { Computer- } \\
\text { based system }\end{array}$ & $\begin{array}{l}\text { CHESS (Comprehensive Health Enhancement Support System) offered information, so- } \\
\text { cial and emotional support, and problem-solving tools for people in health crises (in } \\
\text { HIVIAIDS in this study). Features included: questions and answers, instant library, ask } \\
\text { an expert, getting help/support, discussion group, personal stories, assessment, deci- } \\
\text { sion analysis, and action plan.System was installed on personal computers in subjects' } \\
\text { homes. Communications transmitted via modem to central host computer. }\end{array}$ \\
\hline $\begin{array}{l}\text { Huang, } \\
2013\end{array}$ & telehealth & Phone calls & $\begin{array}{l}\text { Combination of reminder, information dissemination, and communication with health } \\
\text { workers through a biweekly 3-minute phone call service }\end{array}$ \\
\hline $\begin{array}{l}\text { Leon, } \\
2011\end{array}$ & telehealth & Telemedicine & $\begin{array}{l}\text { Virtual Hospital (Multidisciplinary Home Care Telemedicine System): Virtual Consul- } \\
\text { tations, Telepharmacy, Virtual Library and Virtual Community. Virtual consultations had } \\
\text { two levels: consultations conducted via videoconferencing and chat sessions or mess- } \\
\text { age exchanges for emergency or off-schedule consultations. Telepharmacy allowed } \\
\text { the pharmacist to receive electronic prescriptions, to perform virtual consultations } \\
\text { about compliance, adverse events, or interactions, and to send the ART medication to } \\
\text { the patient's home by courier. Virtual library stored validated information about HIV as } \\
\text { links to other web pages. Virtual community provided space to exchange information } \\
\text { about the disease and the project, as well as to share opinions or comment on articles } \\
\text { and news items. }\end{array}$ \\
\hline $\begin{array}{l}\text { Mbuag- } \\
\text { baw, } \\
2012\end{array}$ & mHealth & Text messaging & $\begin{array}{l}\text { Cameroon mobile phone SMS (CAMPS): a weekly standardized motivational text } \\
\text { message for adherence to ART }\end{array}$ \\
\hline $\begin{array}{l}\text { Millard, } \\
2015\end{array}$ & eHealth & $\begin{array}{l}\text { Internet-based } \\
\text { program }\end{array}$ & $\begin{array}{l}\text { Positive Outlook:Online self-management program consisting of a series of informa- } \\
\text { tion modules, goal-setting and action-planning activities and discussion boards, and is } \\
\text { delivered as a peer-facilitated closed group }\end{array}$ \\
\hline $\begin{array}{l}\text { Proes- } \\
\text { chold- } \\
\text { Bell, } 2010\end{array}$ & eHealth & $\begin{array}{l}\text { Health Infor- } \\
\text { mation Ex- } \\
\text { change }\end{array}$ & $\begin{array}{l}\text { Exchanged patient information between care providers among six infectious disease } \\
\text { clinics paired with } 9 \text { case management agencies using electronic health records and } \\
\text { printouts inserted into charts: 1) by care providers in clinical settings, patients' CD4 } \\
\text { counts, viral loads, current medication lists and appointment attendance } 2 \text { ) by care } \\
\text { providers in case management agencies, medication adherence and major life } \\
\text { changes for the patients (e.g., loss of housing) }\end{array}$ \\
\hline $\begin{array}{l}\text { Pyne, } \\
2011\end{array}$ & $\begin{array}{l}\text { eHealth+tele- } \\
\text { health }\end{array}$ & $\begin{array}{l}\text { Web-based } \\
\text { decision sup- } \\
\text { port system + } \\
\text { telephone- } \\
\text { based monitor- } \\
\text { ing }\end{array}$ & $\begin{array}{l}\text { HIV Translating Initiatives for Depression Into Effective Solutions (HITIDES): an offsite } \\
\text { HIV depression care team (a registered nurse depression care manager, pharmacist, } \\
\text { and psychiatrist) delivered collaborative care backed by a Web-based decision support } \\
\text { system plus telephone-based monitoring every } 2 \text { or } 4 \text { weeks. The team communicated } \\
\text { with treating clinicians via electronic medical record progress notes, and communi- } \\
\text { cated with patients via telephoneHITIDES components - participant education and ac- } \\
\text { tivation, assessment of treatment barriers and possible resolutions, depression symp- } \\
\text { tom and treatment monitoring, substance abuse monitoring, and instruction in self- } \\
\text { management }\end{array}$ \\
\hline $\begin{array}{l}\text { Robbins, } \\
2013\end{array}$ & telehealth & Phone calls & $\begin{array}{l}\text { A site-nurse initiated adherence and symptom support telephone calls:initial tele- } \\
\text { phone call was made } 1 \text { to } 3 \text { days after starting ART, and then on weeks } 1,2,3,6,10 \text {, } \\
\text { 14, 18,22, 26, and every } 8 \text { weeks thereafter.The same telephone script was used for } \\
\text { all calls; nurses adapted the calls depending on the patients' adherence issues and } \\
\text { symptoms. }\end{array}$ \\
\hline $\begin{array}{l}\text { Wang, } \\
2010\end{array}$ & telehealth & Phone calls & Phone calls intervention with nurse-delivered home visit (10-20 minutes to an hour) \\
\hline Wu, 2006 & mHealth & $\begin{array}{l}\text { Programmable } \\
\text { mobile device }\end{array}$ & $\begin{array}{l}\text { Disease Management Assistance System (DMAS): a programmable medication rem- } \\
\text { inder device that verbally reminds patients to take medication when due and elec- } \\
\text { tronically records doses self-administered }\end{array}$ \\
\hline
\end{tabular}


Table 3 Summary of Quality of Life instruments used in eligible studies

\begin{tabular}{|c|c|c|c|}
\hline Study & Instrument & Type & Description (domains/subscales/items/scores) \\
\hline $\begin{array}{l}\text { Gustaf- } \\
\text { son, } 1994\end{array}$ & Not reported & Generic & $\begin{array}{l}\text { Eight dimensions: } \\
\text { social support, cognitive functioning, active life, active participating in health } \\
\text { care, negative emotions, depression, physical functioning, and level of energy } \\
\text { Average quality of life score compared }\end{array}$ \\
\hline $\begin{array}{l}\text { Huang, } \\
2013\end{array}$ & $\begin{array}{l}\text { WHOQOL-HIV } \\
\text { BREF }\end{array}$ & $\begin{array}{l}\text { HIV-spe- } \\
\text { cific }\end{array}$ & $\begin{array}{l}\text { Six domains and } 29 \text { items: } \\
\text { 1) } 4 \text { items physical well-being; } \\
\text { 2) } 5 \text { items psychological status; } \\
\text { 3) } 4 \text { items level of independence; } \\
\text { 4) } 4 \text { items social relationships; } \\
\text { 5) } 8 \text { items environment; } \\
\text { 6) } 4 \text { items spirituality/religion/personal beliefs } \\
\text { Score range from 4-20, high score indicates better QoL }\end{array}$ \\
\hline $\begin{array}{l}\text { Leon, } \\
2011\end{array}$ & $\begin{array}{l}\text { Mini International } \\
\text { Neuropsychiatric } \\
\text { Interview (MINI) }\end{array}$ & Generic & $\begin{array}{l}\text { Five domains } \\
\text { mental and physical health, cognitive and social functioning, energy levels and } \\
\text { vitality, perceived social support, sleep and sexuality } \\
130 \text { questions with only "yes" or "no" answers } \\
\text { Score range from 1-100, high score indicates better QoL }\end{array}$ \\
\hline $\begin{array}{l}\text { Mbuag- } \\
\text { baw, } \\
2012\end{array}$ & $\begin{array}{l}\text { Short Form-12 } \\
\text { (SF-12) }\end{array}$ & Generic & $\begin{array}{l}\text { Two composite and } 12 \text { items: } \\
\text { physical health and mental health composite scores ranging from } 0-100 \text {, } \\
\text { where a zero score indicates the lowest level of health measured by the scales } \\
\text { and } 100 \text { indicates the highest level of health }\end{array}$ \\
\hline $\begin{array}{l}\text { Millard, } \\
2015\end{array}$ & $\begin{array}{l}\text { Patient Reported } \\
\text { OutcomesQuality } \\
\text { of Life - HIV } \\
\text { (PROQOL-HIV) }\end{array}$ & $\begin{array}{l}\text { HIV-spe- } \\
\text { cific }\end{array}$ & $\begin{array}{l}\text { Eight domains: } \\
\text { 1) physical health and symptoms; } \\
\text { 2) body change; } \\
\text { 3) social relationships; } \\
\text { 4) intimate relationships; } \\
\text { 5) stigma; } \\
\text { 6) emotional distress; } \\
\text { 7) health concerns, and } \\
\text { 8) treatment impact }\end{array}$ \\
\hline $\begin{array}{l}\text { Proes- } \\
\text { chold- } \\
\text { Bell, } 2010\end{array}$ & $\begin{array}{l}\text { Short Form-36 } \\
\text { (SF-36) }\end{array}$ & Generic & $\begin{array}{l}\text { Medical Outcomes Study Short Form-36 } \\
36 \text { items } \\
\text { Two composite: } \\
\text { physical component summary and the mental component summary } \\
8 \text { subscales: } \\
\text { physical functioning, role functioning (physical and emotional), bodily pain, } \\
\text { general health, vitality, social functioning, and mental health } \\
\text { Ranging from } 0-100, \text { with } 100 \text { indicating better health }\end{array}$ \\
\hline $\begin{array}{l}\text { Pyne, } \\
2011\end{array}$ & $\begin{array}{l}\text { Quality of Well- } \\
\text { Being Self-admin- } \\
\text { istered Scale } \\
\text { (QWB-SA) }\end{array}$ & Generic & $\begin{array}{l}\text { Four domains: } \\
\text { physical activities, social activities, mobility, and symptom/problem complexes } \\
\text { (no description in the study) } \\
\text { The QWB-SA score is derived from general population preference weights and } \\
\text { ranges from death ( } 0.0) \text { to perfect health }(1.0), \text { combined the four domain } \\
\text { scores into a total score }\end{array}$ \\
\hline $\begin{array}{l}\text { Robbins, } \\
2013\end{array}$ & $\begin{array}{l}\text { AIDS Clinical } \\
\text { TrialsGroup } \\
\text { (ACTG) Multidi- } \\
\text { mensional Health } \\
\text { Status and the } \\
\text { Quality of Life } \\
\text { (QL0601-0602) }\end{array}$ & $\begin{array}{l}\text { HIV-spe- } \\
\text { cific }\end{array}$ & $\begin{array}{l}\text { The ACTG QL0601-0602: } \\
\text { QL0601 Overall Health Status Assessment } \\
\text { QL0602 Multidimensional Health Status Assessment } \\
\text { Nine domains with } 21 \text { items: } \\
\text { overall health, general health perceptions, physical functioning, role function- } \\
\text { ing, pain, social functioning, mental health, energy, cognitive functioning } \\
\text { Eight of the } 9 \text { subscales are scored as summated rating scales on a } 0-100 \\
\text { scale where higher scores indicate better health }\end{array}$ \\
\hline
\end{tabular}


Table 3 Continued

\begin{tabular}{|c|c|c|c|}
\hline Study & Instrument & Type & Description (domains/subscales/items/scores) \\
\hline $\begin{array}{l}\text { Wang, } \\
2010\end{array}$ & $\begin{array}{l}\text { WHOQOL-BREF } \\
\text { (Chinese versions) }\end{array}$ & Generic & $\begin{array}{l}\text { 26-item multiple-choice questionnaire (ranging from } 4-20 \text { ) } \\
\text { 1) } 1 \text { item for general QoL and } 1 \text { item for health-related QoL } \\
\text { 2) } 24 \text { items belonging to four domains: } 7 \text { items physical, } 6 \text { items psychological, } \\
3 \text { items social and } 8 \text { items environmental }\end{array}$ \\
\hline $\mathrm{Wu}, 2006$ & $\begin{array}{l}\text { Medical Out- } \\
\text { comes Study HIV } \\
\text { Health Survey } \\
\text { (MOS-HIV) }\end{array}$ & $\begin{array}{l}\text { HIV-spe- } \\
\text { cific }\end{array}$ & $\begin{array}{l}\text { QoL Scales including the MOS-HIV with the Centers for Epidemiologic Studies } \\
\text { Depression Scale (CES-D), Instrumental Activities of Daily Living (IADLs), and } \\
\text { additional role-functioning items } \\
\text { MOS-HIV: } \\
10 \text { dimensions of health-related QoL: } \\
\text { pain, physical function, role function, social function, mental health, energy/fa- } \\
\text { tigue, health distress, cognitive function, health perception, and overall QoL, } \\
\text { ranging from } 0 \text { indicating the lowest possible score (poorest health) to } 100 \text { in- } \\
\text { dicating the highest possible score (best health) } \\
\text { CES-D: } \\
20 \text { items of guilt and loneliness, appetite, sleep, psychomotor problems, mood, } \\
\text { and depressive symptoms, using a four-point scale that ranges from } 0 \text { (rarely } \\
\text { or none of the time) to } 3 \text { (most or all of the time) } \\
\text { IADLs: } \\
15 \text { items assessed patients' abilities to perform everyday tasks such as dress- } \\
\text { ing, bathing, money management, home care, and eating, ranging from } 0 \text { (yes, } \\
\text { without help) to } 2 \text { (no, unable to do). } \\
\text { Additional role function items: } 4 \text { items from the SF-36 }\end{array}$ \\
\hline
\end{tabular}




\section{References}

1. World Health Organization. HIV/AIDS 2016. Available from: http://www.who.int/mediacentre/fact sheets/fs360/en/.

2. Clayson DJ, Wild DJ, Quarterman P, Duprat-Lomon I. A Comparative Review of Health-Related Qualityof-Life Measures for Use in HIV/AIDS Clinical Trials. PharmacoEconomics 2006; 24(8): 751-765.

3. Clayson DJ, Wild DJ, Quarterman P, Duprat-Lomon I, Kubin M, Coons SJ. A comparative review of health-related quality-of-life measures for use in HIV/AIDS clinical trials. PharmacoEconomics 2006; 24(8): 751-765.

4. Development of the World Health Organization WHOQOL-BREF quality of life assessment. The WHOQOL Group. Psychological medicine 1998; 28(3): 551-558.

5. Liping M, Peng X, Haijiang L, Lahong J, Fan L. Quality of Life of People Living with HIV/AIDS: A CrossSectional Study in Zhejiang Province, China. PloS one 2015; 10(8):e0135705.

6. de Boer-van der Kolk IM, Sprangers MA, Prins JM, Smit C, de Wolf F, Nieuwkerk PT. Health-related quality of life and survival among HIV-infected patients receiving highly active antiretroviral therapy: a study of patients in the AIDS Therapy Evaluation in the Netherlands (ATHENA) Cohort. Clinical Infectious Diseases 2010; 50(2): 255-263.

7. Degroote S, Vogelaers D, Vandijck DM. What determines health-related quality of life among people living with HIV: an updated review of the literature. Archives of Public Health 2014; 72(1): 40.

8. Schnall R, Liu J, Cho H, Hirshfield S, Siegel K, Olender S. A health-related quality of life measure for use in patients with HIV: A validation study. AIDS Patient Care and STDs. 2016. doi: 10.1089/apc.2016.0252.

9. Jongbloed K, Parmar S, van der Kop M, Spittal PM, Lester RT. Recent Evidence for Emerging Digital Technologies to Support Global HIV Engagement in Care. Current HIV/AIDS Reports 2015; 12(4): 451-461.

10. Gardner EM, McLees MP, Steiner JF, Del Rio C, Burman WJ. The spectrum of engagement in HIV care and its relevance to test-and-treat strategies for prevention of HIV infection. Clinical Infectious Diseases 2011; 52(6): 793-800.

11.Schnall R, Bakken S, Rojas M, Travers J, Carballo-Dieguez A. mHealth Technology as a Persuasive Tool for Treatment, Care and Management of Persons Living with HIV. AIDS and Behavior 2015; 19(2): 81-89.

12.Schnall R, Wantland D, Velez O, Cato K, Jia H. Feasibility testing of a web-based symptom self-management system for persons living with HIV. The Journal of the Association of Nurses in AIDS Care: JANAC 2014; 25(4): 364-71.

13. Finitsis DJ, Pellowski JA, Johnson BT. Text message intervention designs to promote adherence to antiretroviral therapy (ART): a meta-analysis of randomized controlled trials. PloS one 2014; 9(2): e88166.

14. Horvath T, Azman H, Kennedy GE, Rutherford GW. Mobile phone text messaging for promoting adherence to antiretroviral therapy in patients with HIV infection. The Cochrane Database of Systematic Reviews 2012(3): CD009756.

15. Mbuagbaw L, Mursleen S, Lytvyn L, Smieja M, Dolovich L, Thabane L. Mobile phone text messaging interventions for HIV and other chronic diseases: an overview of systematic reviews and framework for evidence transfer. BMC Health Services Research 2015; 15: 33.

16. Collier AC, Ribaudo H, Mukherjee AL, Feinberg J, Fischl MA, Chesney M. A randomized study of serial telephone call support to increase adherence and thereby improve virologic outcome in persons initiating antiretroviral therapy. The Journal of Infectious Diseases 2005; 192(8): 1398-1406.

17. Reynolds NR, Testa MA, Su M, Chesney MA, Neidig JL, Frank I, Smith S, Ickovics J, Robbins GK. Telephone support to improve antiretroviral medication adherence: a multisite, randomized controlled trial. Journal of Acquired Immune Deficiency Syndromes 2008; 47(1): 62-68.

18. Vidrine DJ, Marks RM, Arduino RC, Gritz ER. Efficacy of cell phone-delivered smoking cessation counseling for persons living with HIV/AIDS: 3-month outcomes. Nicotine \& Tobacco Research 2012; 14(1): 106-110.

19. Kempf M-C, Huang C-H, Savage R, Safren SA. Technology-Delivered Mental Health Interventions for People Living with HIV/AIDS (PLWHA): a Review of Recent Advances. Current HIV/AIDS Reports 2015; 12(4): 472-480.

20.Schnall R, Cimino JJ, Bakken S. Development of a Prototype Continuity of Care Record with Context-Specific Links to Meet the Information Needs of Case Managers for Persons Living with HIV. International Journal of Medical Informatics 2012; 81(8): 549-555.

21. Mannheimer SB, Matts J, Telzak E, Chesney M, Child C, Wu AW, Friedland G. Quality of life in HIV-infected individuals receiving antiretroviral therapy is related to adherence. AIDS Care 2005; 17(1): 10-22.

22.Lorenz KA, Shapiro MF, Asch SM, Bozzette SA, Hays RD. Associations of symptoms and health-related quality of life: findings from a national study of persons with HIV infection. Annals of Internal Medicine 2001; 134(9 Pt 2): 854-860. 
23. Abboud S, Noureddine S, Huijer HA, DeJong J, Mokhbat J. Quality of life in people living with HIV/AIDS in Lebanon. AIDS Care 2010; 22(6): 687-696.

24. Bastardo YM, Kimberlin CL. Relationship between quality of life, social support and disease-related factors in HIV-infected persons in Venezuela. AIDS Care 2000; 12(5): 673-684.

25. Chin JJ, Botsko M, Behar E, Finkelstein R. More than ancillary: HIV social services, intermediate outcomes and quality of life. AIDS Care 2009; 21(10): 1289-1297.

26. Schnall R, Mosley JP, Iribarren SJ, Bakken S, Carballo-Dieguez A, Brown Iii W. Comparison of a UserCentered Design, Self-Management App to Existing mHealth Apps for Persons Living With HIV. JMIR mHealth and uHealth 2015; 3(3): e91.

27. World Health Organization. eHealth 2016. Available from: http://www.who.int/topics/ehealth/en/.

28. HealthIT.gov. What is telehealth? How is telehealth different from telemedicine? 2014. Available from: https://www.healthit.gov/providers-professionals/faqs/what-telehealth-how-telehealth-different-telemedi cine.

29. World Health Organization. Digital health in TB care and control: Key definitions 2016. Available from: http://www.who.int/tb/areas-of-work/digital-health/definitions/en/.

30. Moher D, Liberati A, Tetzlaff J, Altman DG. Preferred reporting items for systematic reviews and metaanalyses: The PRISMA statement. Annals of Internal Medicine 2009; 151(4): 264-269.

31. Covidence 2016. Available from: http://www.covidence.org/.

32.Higgins JPT, Altman DG, Gøtzsche PC, Jüni P, Moher D, Oxman AD, Savović J, Schulz KF, Weeks L, Sterne JAC. The Cochrane Collaboration's tool for assessing risk of bias in randomised trials. BMJ 2011; 343: d5928

33. Gustafson DH, Hawkins RP, Boberg EW, Bricker E, Pingree S, Chan CL. The use and impact of a computer-based support system for people living with AIDS and HIV infection. Proceedings / the Annual Symposium on Computer Application [sic] in Medical Care Symposium on Computer Applications in Medical Care 1994: 604-608.

34. Huang D, Sangthong R, McNeil E, Chongsuvivatwong V, Zheng W, Yang X. Effects of a Phone Call Intervention to Promote Adherence to Antiretroviral Therapy and Quality of Life of HIV/AIDS Patients in Baoshan, China: A Randomized Controlled Trial. AIDS Research and Treatment 2013; 2013(3): 1-9.

35. Leon A, Caceres C, Fernandez E, Chausa P, Martin M, Codina C, Rousaud A, Blanch J, Mallolas J, Martinez E, Blanco JL, Laguno M, Larrousse M, Milinkovic A, Zamora L, Canal N, Miro JM, Gatell JM, Gomez EJ, Garcia F. A new multidisciplinary home care telemedicine system to monitor stable chronic human immunodeficiency virus-infected patients: a randomized study. PloS one 2011; 6(1): e14515.

36. Mbuagbaw L, Thabane L, Ongolo-Zogo P, Lester RT, Mills EJ, Smieja M, Dolovich L, Kouanfack C. The Cameroon Mobile Phone SMS (CAMPS) trial: a randomized trial of text messaging versus usual care for adherence to antiretroviral therapy. PloS one 2012; 7(12): e46909.

37. Millard T, McDonald K, Girdler S, Slavin S, Elliot J. Online self-management for gay men living with HIV: a pilot study. Sexual Health 2015; 12(4): 308-314.

38. Proeschold-Bell RJ, Belden CM, Parnell H, Cohen S, Cromwell M, Lombard F. A randomized controlled trial of health information exchange between human immunodeficiency virus institutions. Journal of Public Health Management and Practice: JPHMP 2010; 16(6): 521-528.

39. Pyne JM, Fortney JC, Curran GM, Tripathi S, Atkinson JH, Kilbourne AM, Hagedorn HJ, Rimland D, Rodriguez-Barradas MC, Monson T, Bottonari KA, Asch SM, Gifford AL. Effectiveness of collaborative care for depression in human immunodeficiency virus clinics. Archives of Internal Medicine 2011; 171(1): 23-31.

40. Robbins GK, Testa MA, Su M, Safren SA, Morse G, Lammert S, Shafer RW, Reynolds NR, Chesney MA. Site nurse-initiated adherence and symptom support telephone calls for HIV-positive individuals starting antiretroviral therapy, ACTG 5031: substudy of ACTG 384. HIV Clinical Trials 2013; 14(5): 235-253.

41. Wang H, Zhou J, Huang L, Li X, Fennie KP, Williams AB. Effects of nurse-delivered home visits combined with telephone calls on medication adherence and quality of life in HIV-infected heroin users in Hunan of China. Journal of Clinical Nursing 2010; 19(3-4): 380-388.

42. Wu AW, Snyder CF, Huang IC, Skolasky R, McGruder HF, Celano SA, Selnes OA, Andrade AS. A randomized trial of the impact of a programmable medication reminder device on quality of life in patients with AIDS. AIDS Patient Care and STDs 2006; 20(11): 773-781.

43. Ware J. The MOS 36-Item Short-Form Health Survey (SF-36). In: Sederer, LI.; Dickey, B., editors. Outcomes Assessment in Clinical Practice. Williams and Wilkins; Baltimore: 1996. p. 61-64.

44. Rehab Measures: Short Form 12 item (version 2) Health Survey [cited 2015 November 25th]. Available from: http://www.rehabmeasures.org/Lists/RehabMeasures/DispForm.aspx?ID=1149.

45. Ware J, Kosinski M, Dewey J. How to Score Version Two of the SF- $36^{\circ}$ Health Survey. Lincoln (RI): QualityMetric Incorporated2000. 
46.The M.I.N.I. Medical Outcome Systems2014 [cited 2015 November 25th]. Available from: http://www. medical-outcomes.com/index/mini.

47. Reliability and validity of Japanese version of the Mini冈International Neuropsychiatric Interview. Psychiatry and Clinical Neurosciences 2005; 59(5): 517-526.

48. Sheehan DV, Lecrubier Y, Sheehan KH, Amorim P, Janavs J, Weiller E, Hergueta T, Baker R, Dunbar GC. The Mini-International Neuropsychiatric Interview (M.I.N.I.): the development and validation of a structured diagnostic psychiatric interview for DSM-IV and ICD-10. The Journal of Clinical Psychiatry 1998; 59(Suppl. 20): 22-33; quiz 4-57.

49. Fang CT, Hsiung PC, Yu CF, Chen MY, Wang JD. Validation of the World Health Organization quality of life instrument in patients with HIV infection. Quality of Life Research 2002; 11(8): 753-762.

50.WHO. "WHOQOL-HIV BREF, Geneva, Switzerland," Mental Health: Evidence and Research Department of Mental Health and Substance Dependence 2002. Available from: http://www.who.int/mental_health/ media/en/613.pdf.

51.Duracinsky M, Herrmann S, Berzins B, Armstrong AR, Kohli R, Le Coeur S, Diouf A, Fournier I, Schechter M, Chassany O. The development of PROQOL-HIV: an international instrument to assess the health-related quality of life of persons living with HIV/AIDS. Journal of Acquired Immune Deficiency Syndromes 2012; 59(5): 498-505.

52.Wu AW, Rubin HR, Mathews WC, Ware JE, Jr., Brysk LT, Hardy WD, Bozzette SA, Spector SA, Richman DD. A health status questionnaire using 30 items from the Medical Outcomes Study. Preliminary validation in persons with early HIV infection. Medical Care 1991; 29(8): 786-798.

53. Naughton M, Wiklund I. Dimension-specific instruments that may be used across cultures. In: Spilker B. ed. Quality of Life and Pharmacoeconomics in Clinical Trials, Second Edition. Philadelphia: LippincottRaven Publishers, 1996: 633-658.

54. Marder K, Albert SM, McDermott MP, McArthur JC, Schifitto G, Selnes OA, Sacktor N, Stern Y, Palumbo D, Kieburtz K, Cohen B, Orme C, Epstein LG. Inter-rater reliability of a clinical staging of HIV-associated cognitive impairment. Neurology 2003; 60(9): 1467-1473.

55. Clinical Trials Behavioral and Social Sciences Research [cited 2015 December 2nd]. Available from: http://www.esourceresearch.org/eSourceBook/ClinicalTrials/4Endpoints/tabid/200/Default.aspx.

56. Higgins J, Green Se. Cochrane Handbook for Systematic Reviews of Interventions Version 5.1.0 [updated March 2011]. The Cochrane Collaboration, 2011. Available from http://handbook.cochrane.org. 2011.

57.Lester RT, Ritvo P, Mills EJ, Kariri A, Karanja S, Chung MH, Jack W, Habyarimana J, Sadatsafavi M, Najafzadeh M, Marra CA, Estambale B, Ngugi E, Ball TB, Thabane L, Gelmon LJ, Kimani J, Ackers M, Plummer FA. Effects of a mobile phone short message service on antiretroviral treatment adherence in Kenya (WelTel Kenya1): a randomised trial. The Lancet 2010; 376(9755): 1838-1845.

58. Sorensen JL, Haug NA, Delucchi KL, Gruber V, Kletter E, Batki SL, Tulsky JP, Barnett P, Hall S. Voucher Reinforcement Improves Medication Adherence in HIV-Positive Methadone Patients: A Randomized Trial. Drug and Alcohol Dependence 2007; 88(1): 54-63.

59.van der Kop ML. The effect of weekly short message service communication on patient retention in care in the first year after HIV diagnosis: study protocol for a randomised controlled trial (WelTel Retain). BMJ Open 2013; 3(6): e003155.

60. Christopoulos KA, Riley ED, Tulsky J, Carrico AW, Moskowitz JT, Wilson L, Coffin LS, Falahati V, Akerley J, Hilton JF. A text messaging intervention to improve retention in care and virologic suppression in a U.S. urban safety-net HIV clinic: study protocol for the Connect4Care (C4C) randomized controlled trial. BMC Infectious Diseases 2014; 14: 718.

61.Pildal J, Hrobjartsson A, Jorgensen KJ, Hilden J, Altman DG, Gotzsche PC. Impact of allocation concealment on conclusions drawn from meta-analyses of randomized trials. International journal of epidemiology 2007; 36(4): 847-857.

62. Fjeldsoe BS, Marshall AL, Miller YD. Behavior Change Interventions Delivered by Mobile Telephone Short-Message Service. American Journal of Preventive Medicine 2009; 36(2): 165-173.

63. Heckman TG. The chronic illness quality of life (CIQOL) model: Explaining life satisfaction in people living with HIV disease. Health Psychology 2003; 22(2): 140-147.

64. Noordzij M, Tripepi G, Dekker FW, Zoccali C, Tanck MW, Jager KJ. Sample size calculations: basic principles and common pitfalls. Nephrology, Dialysis, Transplantation 2010; 25(5): 1388-1393.

65. World Health Organization. International Classification of Functioning, Disability and Health (ICF). 